\title{
Numerical Simulation of Fire Resistance Test of a Concrete Slab
}

\author{
KAZUNORI HARADA and TOSHIO TERAI \\ Department of Architecture \\ Kyoto University \\ Kyoto, Japan
}

ABSTRACT

When concrete is intensely heated during fire, creeping of temperatures in the region of $100^{\circ} \mathrm{C}$ are often observed. To simulate this phenomenon, a simple mathematical model for heat and moisture transfer in concrete is presented. The model takes into account the conservation of heat, water vapor and liquid water. As to the water contained in concrete, reversible evaporation of adsorbed water in the pores and irreversible thermal decomposition of chemically acsorbed water in cement paste are considered.

These equations are so-called stiff equations and rather difficult to solve. For numerical stability, they are formulated by using integral equations coupled with the diagonally implicit Runge-Kutta method. Humerical solution of the model is compared with the experimental data.

\section{KEY WORDS}

Fire Resistance of Concrete, Wumerical Simulation, Evaporation of later, Decomposition of Cenent Paste

\section{IHTHODUCTIOK}

When predicting the temperature history of concrete in case of fire, Kawagoe/1/, Wakamatsu/2/,Fujii/3/ assumed that liquid water in concrete evaporates, taking latent heat of vaporization at $100^{\circ} \mathrm{C}$. In these models, the conservation of water vapor is not included. In spite of this simplification, these models give reasonable results for engineering purposes. Models which take into account the movement of water vapor and Iiquid water are also presented by many authors(Farnathy $/ 4 /$, Matsumoto $/ 5 /$, luang et al./6/, Sahota et al./7/, Dayan et al./8/). They solve sophisticated equations of simultaneous heat and moisture transfer.

The model we treat here is a simple diffusion model. It consists of a heat transfer equation, conservation of water vapor and liquid water in the pores. As to the water contained in concrete, not only the evaporation of physically adsorbed water, but also thermal decomposition of chemically adsorbed water in cement paste are considered.

\section{DEFTNITION OH POROUS SYSTEM}

Concrete is a porous material made of cement paste and aggregate. A part of the water is bonded to the cement as chemically adsorbed water, 
and the rest is contained in the pores as liquid water and water vapor. Water vapor is mixed with air.

This porous system is shown in igure 1. The water content is defined as the sum of physically adsorbed water and chemically adsorbed water.

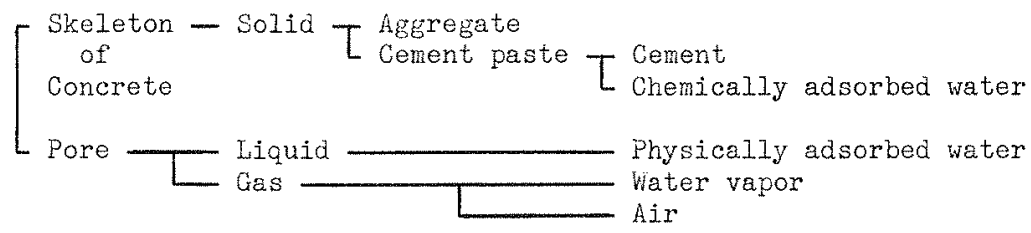

\section{Figure 1. Definition of Porous System}

To simplify the heat and mass transfer in this system, the following assumptions are made.

1) Heat flows through the solid matrix only. Heat flux due to convection in the pores is neglected.

2) Water vapor is transferrea by diffusion only. Convection aue to total pressure gradient is neglected.

3) Liquid water is transferred by diffusion only.

4) Air is purged in the early stage of heating. Therefore, treatment as a binary mixture of water vapor and dry air is omitted.

GOVLRNING EQUATTONS

The governing equations for conservation of heat, water vapor and liquid water are

$$
\begin{aligned}
& \rho c \frac{\partial \theta}{\partial t}=\nabla(\lambda \nabla \theta)-L_{\text {Ioc }}, \\
& \rho_{0} \frac{\partial v}{\partial t}=\nabla\left(\rho_{0} D_{v} \nabla v\right)+R_{I o c}, \\
& \rho_{0} \frac{\partial w}{\partial t}=\nabla\left(\rho_{0} D_{w} \nabla w\right)-R_{I o c} .
\end{aligned}
$$

The source term, the rate of local evaporation, in equations $(1),(2)$ and (3), is defined as

$$
R_{\text {loc }}=\gamma \mathrm{w}\left(\mathrm{v}_{\mathrm{eq}}-\mathrm{v}\right)+\rho_{0} A_{\mathrm{d}} \mathrm{w} \exp \left(-\mathrm{E}_{\mathrm{d}} / \mathrm{RT}\right) \text {. }
$$

The first term in equation (4) represents reversible physical adsorption and desorption of water. Equilibrium vapor pressure is calculated from Erenkel-halsey equation/9/,

$$
\log \left(\mathrm{p}_{\mathrm{v}, e q} / \mathrm{P}_{\mathrm{v}, \mathrm{sat}}\right)=-\mathrm{C}_{\mathrm{s}} /\left(\mathrm{L}^{\mathrm{ns}}\right) \text {. }
$$
Saturated vapor pressure of free water $\mathrm{P}_{\mathrm{v}}$, sat, is assumea to be given
by the Clausius-clapeyron equation

$$
\mathrm{P}_{\mathrm{v}, \mathrm{sat}}=\mathrm{A}_{\mathrm{v}} \exp \left(-\mathrm{B}_{\mathrm{v}} / \mathrm{T}\right)
$$

with $A=0.9243 \mathrm{E}+11, \mathrm{~B}=0.5128 \mathrm{E}+4$. Regarding water vapor as perfect gas, $v_{e q}$ becomes from equations $(5)$ and $(6)$ 


$$
v_{e q}=\varepsilon_{e f f} A_{v} \exp \left(-B_{v} / T-C_{s} /\left(P_{w}{ }^{n_{S}}\right)\right) /\left(\rho_{O} R_{v} T\right) \cdot
$$

The second term in equation (4) represents the thermal decomposition of chemically adsorbed water. This takes place at high temperature irreversibly. However, since detailed information on the mechanism of thermal decomposition is not available, we applied empirical Arrhenius equations. Coefficients $A_{d}$ and $\mathrm{E}_{d}$ can be determined by thermo-gravimetric analysis.

At normal temperature, the second term is negligible in comparison with the first, but at a high temperature (about $100^{\circ} \mathrm{C}$ ), the orders of these two terms become comparable, and at a still higher temperature, the second becomes dominant.

Boundary Conditions

Boundary conditions are given in order to fit to the experiments described later (See Figure 3).

Exposed Surface. In the test of the composite slab, the exposed surface is covered with a steel plate, therefore

$$
-\lambda \frac{\partial \theta}{\partial n}=h_{f}\left(\theta_{f}-\theta\right), \frac{\partial v}{\partial n}=\frac{\partial w}{\partial n}=0 . \quad(8),(9),(10)
$$

Unexposed Surface. At the unexposed surface, the transfer of heat and water vapor to ambient air are considered, therefore

$$
\begin{aligned}
& -\lambda \frac{\partial \theta}{\partial n}=h_{a m b}\left(\theta_{a m b}-\theta\right), \\
& -\rho_{0} D_{v} \frac{\partial v}{\partial n}=h_{v, a m b}\left(v_{a m b}-v\right), \frac{\partial w}{\partial n}=0 .
\end{aligned}
$$

In these equations, symbol $\mathrm{n}$ denotes inward normal.

\section{NUNERTCAL PROCEDURE}

Governing equations (1) to (13) are to be solved numerically. For numerical stability, we transformed to integral equations, and used the implicit kunge-Kutta method. To save space, only the main points for equation (1) will be shown. The same procedure should be applied to equations (2) and (3).

Transformation into an Integral Equation

To be applicable to the two dimensional problens, two dimensional formulations are described as follows. However, the calculations are carried out for the one dimensional case to compare then with the experiments.

'Ihe fundamental solution of the two ainensional Laplace equation is

$$
G_{\mathrm{pq}}=\frac{1}{2 \pi} \log \left(\frac{1}{r_{\mathrm{pq}}}\right)
$$




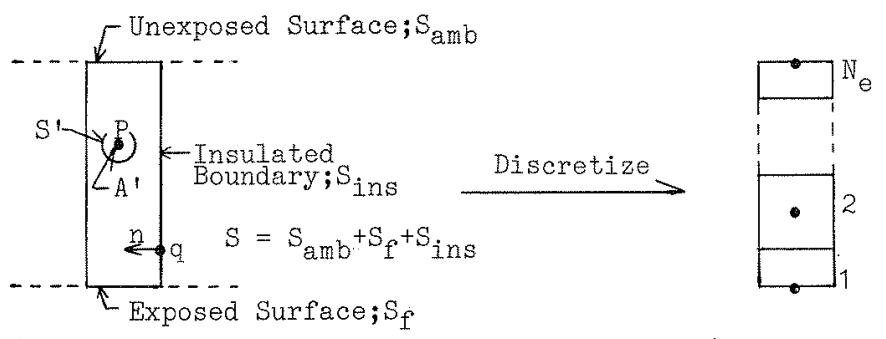

a) Domain of Analysis $\quad$ b) Discrete System

Figure 2. Domain of Analysis

Here, $r_{p q}$ is the distance from the reference point $p$ to the moving point $\mathrm{c}_{\mathrm{i}} \mathrm{G}_{\mathrm{pq}} \mathrm{pq}_{\text {satisfies }} \nabla^{2} \mathrm{G}_{\mathrm{pq}}=0$, when $\mathrm{r}_{\mathrm{pq}} \neq 0$. Rearranging equation (1) gives

$$
\nabla^{2} \theta=\frac{\rho c}{\lambda} \frac{\partial \theta}{\partial t}-\frac{\nabla \lambda \nabla \theta-L R_{I o c}}{\lambda}
$$

In order to apply Green's formula, consider the domain of analysis $A$, as shown in Figure 2a). The singular point should be excluded frori $\dot{A}$ by $a$ circular domain $A^{\prime}$, whose center is $p$ and its radius is $r^{\prime}$.

Green's formula for the domain $A-A^{\prime}$ and its boundary $S+S^{\prime}$, with inward norlial $\mathrm{n}$, is

$$
\iint_{A-A^{1}}\left(\theta \nabla^{2} G_{p q}-G_{p q} \nabla^{2} \theta\right) d A=-\int_{S+S^{\prime}}\left(\frac{\partial q_{p q}}{\partial n} \theta-\frac{\partial \theta}{\partial n} G_{p q}\right) d s .
$$

Substituting equations (8),(11),(14) and (15) into equation (16), and letting $x^{\prime}$ tend to zero, gives

$$
\begin{aligned}
& \iint_{A} G_{p q} \frac{\rho c}{\lambda} \frac{\partial \theta}{\partial t} d A=\iint_{A} G_{p q} \frac{\nabla \lambda \nabla \theta-L R_{l o c}}{\lambda} d A \\
& +\int_{S_{f^{*}}} G_{p q} \frac{h_{f}}{\lambda}\left(\theta_{f^{*}}-\theta\right) d S+\int_{S_{a m b}} G_{p q} \frac{h_{a m b}}{\lambda}\left(\theta_{a m b}-\theta\right) d S \\
& +\int_{S} \frac{\partial G_{p q}}{\partial n} \theta d S-\alpha \theta_{p} .
\end{aligned}
$$

$\alpha$ is unity when point $\mathrm{p}$ is in the donain $\mathrm{A}, 0.5$ when $\mathrm{p}$ converses to the smooth boundary $\mathrm{S}$.

Space Discretization

Dividing the domain A into rectangular elements as ohow in Higure 2b), and assuming that temperature, material properties and rate of local evaporation are constant in each element, equation (1'7) can be reauced to the system of ordinary differential equations. The same procedure is applied to equations (2) and (3), and we get 


$$
\left.\frac{\partial u}{\partial t}\right)=f(u, t) \text {. }
$$

Where, symbol u denotes vector of unknown variables

$$
u=\left\{\theta_{1}, \theta_{2}, \ldots, v_{1}, v_{2}, \ldots, w_{1}, w_{2} \ldots\right\}^{\mathrm{T}} .
$$

Time Integration

Next, equation(18) is integrated with respect to time. Interration is carried out iy the Diagonally Inplicit Runge-Kutta schene of two stages(DIKk22)/10/ to save computing time. The scheme is defined with two quadrature points $t_{n, i}\left(=t_{n}+\Delta t \tau_{i}\right)$ and their weights $b_{i}$

$$
u_{n+1}=u_{n}+\Delta t \sum_{i=1}^{2} b_{i} f\left(u_{n, i}, t_{n, i}\right) \text {. }
$$

In this equation, function $f$ is evaluated by $u_{n, i}$. These values are not known at the beginning of the time step. equations are to be solved to get $u_{n, i}$.

$$
\begin{aligned}
& u_{n, 1}=u_{n}+\Delta t a_{11} f\left(u_{n, 1}, t_{n, 1}\right) \\
& u_{n, 2}=u_{n}+\Delta t \sum_{j=1}^{2} a_{2 j} f\left(u_{n, j}, t_{n, j}\right)
\end{aligned}
$$

The values of $u_{n, i}$ obtained in this way, are used in equation (20) to get $u_{n+1} \cdot$

$$
\begin{array}{ll}
\text { Coeificients } a_{i j}, b_{i}, \tau_{i} \text { are } & \\
a_{11}=0.29289, & \tau_{1}=0.29289, \\
a_{21}=0.70711, a_{22}=0.29289, & \tau_{2}=1.0, \\
b_{1}=0.70711, b_{2}=0.29289 . &
\end{array}
$$

MATEIAL PROFTRTLS AND EOULDARY CORDTTION PARAMETERS/11/

Niaterial properties and boundary condition parameters used in the numerical calculations are listed in the Table 1. Three types of furnace temperature histories are used in the calculations as described in the next section.

\section{OUTLINE OF EXPERIMENTAL PROCEDURES/12/}

Experiments were carried out in accordance with JIS A 1304, standard fire test procedure/13/. The specimen size is $880 \times 1000 \times 100 \mathrm{~mm}$. The specimen's bottom and sides are covered with $1.6 \mathrm{~mm}$ thick steel plate to simulate a composite floor(deck plate). The specimen is horizontally suspended by wire ropes from a load cell, and its bottom surface is heated. The weight is continuously recorded during the test. Thermocouples are located on the steel plate, on the bottom surface of the concrete, at $25,50,75 \mathrm{~mm}$ from the bottom of the concrete, and on the top surface(Figure 3).

Experiment No.A. The furnace temperature is regulated to act in accordance with the standard furnace temperature. Heating time was 150 minutes. 
MATERTAL PROPEETIES

$$
\begin{array}{lclc}
\lambda=-1.971 \mathrm{E}-9 \theta^{3}+4.522 \mathrm{E}-6 \theta^{2} & \rho_{0} & 2200 . \\
& -3.898 \mathrm{E}-3 \theta+2.189 & \varepsilon_{0} & 0.4 \\
\mathrm{C} & 921 . & \gamma & 7.2 \mathrm{E}+8 \\
\mathrm{D}_{\mathrm{v}} & 1.94 \mathrm{E}-5 & \mathrm{D}_{\mathrm{w}} & 5.56 \mathrm{E}-10 \exp (19.2 \mathrm{w}) \\
\mathrm{C}_{\mathrm{S}} & 0.1892 & \mathrm{n}_{\mathrm{S}} & 2.01 \\
\mathrm{~A}_{\mathrm{d}} & 1.08 \mathrm{E}+11 & \mathrm{E}_{\mathrm{d}} / \mathrm{R} & 8331 .
\end{array}
$$

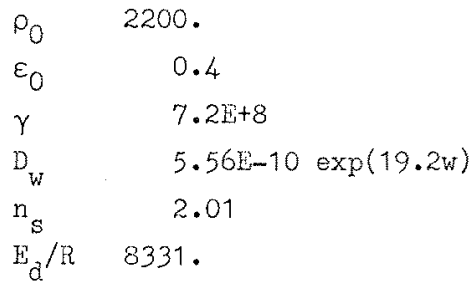

BOUNDARY CONDITIONS

$$
\begin{array}{llll}
h_{f}=4.65+8.591-9\left(\mathrm{~T}_{f}{ }^{4}-\mathrm{T}_{\mathrm{s}}{ }^{4}\right) /\left(\mathrm{T}_{\mathrm{f}}-\mathrm{T}_{\mathrm{s}}\right) & & \\
\mathrm{h}_{\mathrm{amb}} & 23 . & \theta_{\mathrm{amb}} & 20.0 \\
h_{\mathrm{v}, \mathrm{amb}} & 2.44 & \mathrm{v}_{\mathrm{amb}} & 6.2 \mathrm{~L}-6
\end{array}
$$

TIMES INCREWMII
$\Delta t$
$60 \mathrm{Sec}$

IHITIAL VALULE

$$
\begin{aligned}
& \theta_{\text {ini }} 20.0 \\
& v_{\text {ini }} 0.245 \mathrm{E}-5 \\
& w_{\text {ini }} 0.087 \text { (No.A), } 0.082\left(\mathrm{NO}_{0} \mathrm{~B}\right), 0.077 \text { (No.C) }
\end{aligned}
$$

\section{Table 1. List of Parameter Values used.}

Experiment No.B. The furnace temperature is regulated to 90 percent of the standard furnace temperature. Heating time was prolonged to 164 minutes. Experiment No.C. The furnace temperature is regulated to 110 per cent of the standard furnace temperature. Heating time was 136 minutes.

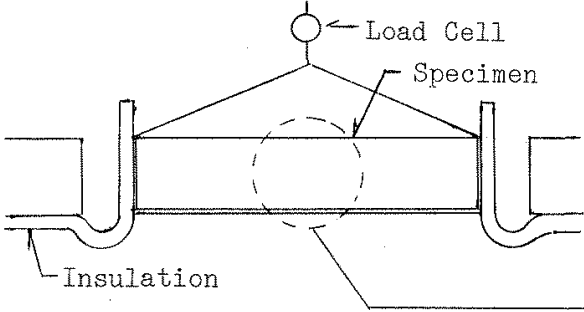

Furnace

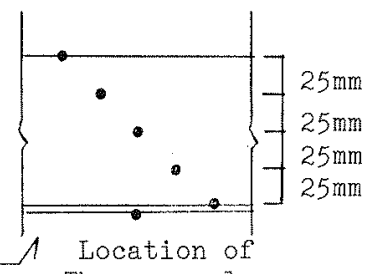

Thermocouples

Eigure 3. Experimental Set-ip

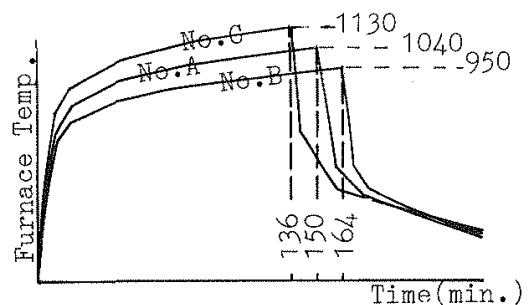

Time-Temperature Area

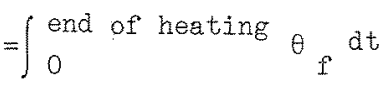

$=$

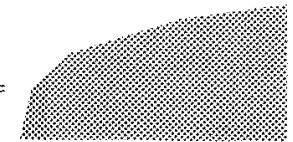

Figure 4. Furnace Temperature Histories. 
In these three experiments, the "line-Pemperature area"(Figure 4 ) is kept constant, but the temperature itself differs $\pm 10 \%$. Current JIS regards these three heating conditions to be within the error tolerance.

The initial water content of the three specimens varied slightly.

\begin{tabular}{|c|c|c|c|c|}
\hline specimen wo: & & 4 & 7 & $\mathrm{C}$ \\
\hline Age of Specimen & (Days) & 69 & 76 & 82 \\
\hline Initial hater Content & $(\%)$ & 8.7 & 8.2 & 7.7 \\
\hline Heating Rate & $(\%)$ & 100 & 90 & 110 \\
\hline Heating Period & (min.) & 150 & 164 & 136 \\
\hline
\end{tabular}

Table 2 Condition of lxperiments

DISCUSSTON

Measured and calculated temperature histories are shom in Figures 5a),6a) and 7a). These figures show that the calculated results are in reasonable agreement with the measured data. The main features are,

1) Maximum temperatures of each point is first reached in experinent No.C, and its value is also highest.

2) Creeping temperature is about 100 to $140^{\circ} \mathrm{C}$ both in experiments and calculations. Fhese temperatures become higher when the measuring point is nearer to the exposed surface.

In Figures 5b), 6b) and 7b), vapor content histories are shown. In
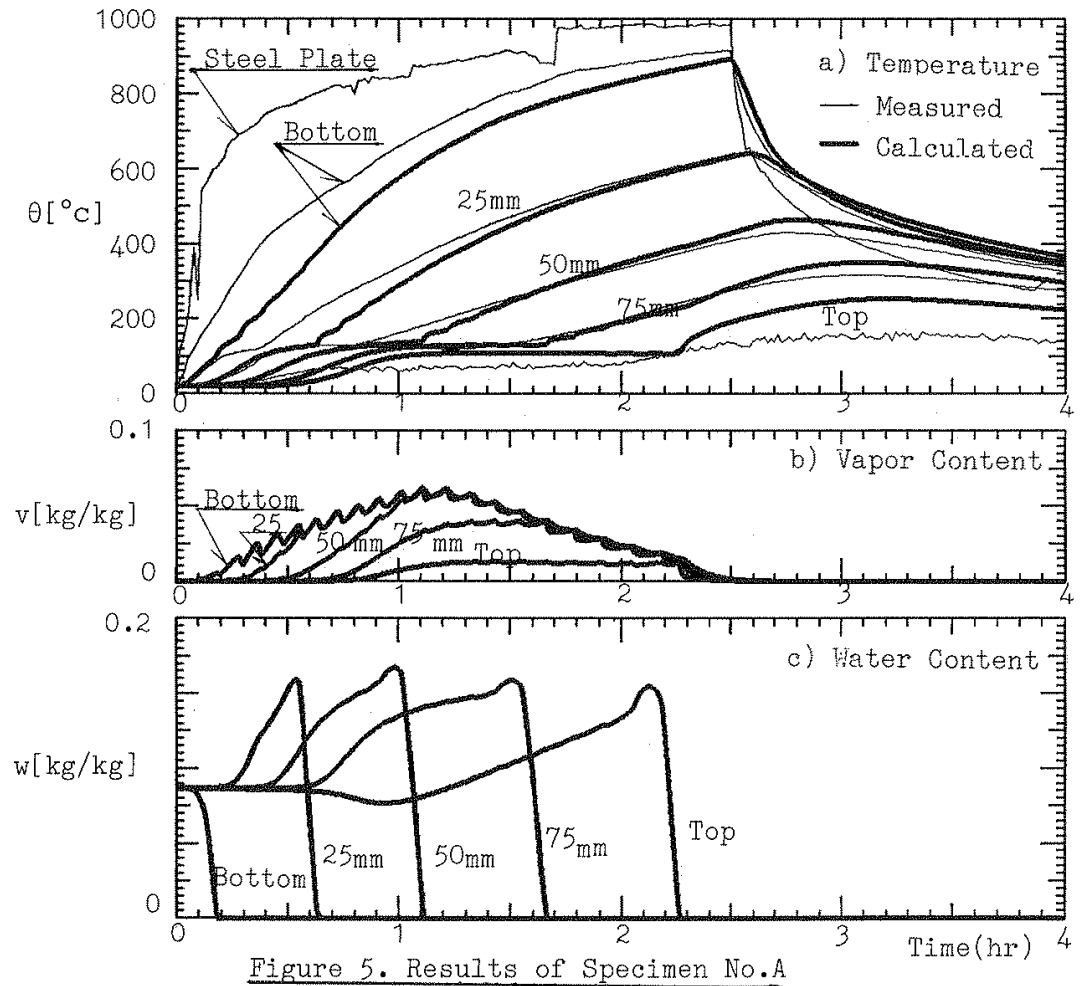
these figures, small oscillations appear. They are not intrinsic, but are the effect of discretization. Whey can be reduced by using anall gria sizes and small time increments. However, the computing time then becomes longer. (Computing time was about 80 seconds for each calculation)

In Figures 5c),6e) and 70 ), the history of water content is shom. Water content of each point initially rises due to tile diflusion of hot water vapor from the zone of exposed surface, but fidis as the temperature of the point begins to rise.

The measured and calculated weight loss of each specimen are shown in Figure 8. The weight loss is calculated by the following equation,

$$
w_{\text {IOSS }}(t)=\iiint_{V} \rho_{0}\left(w_{\text {ini }}-w(t)\right) d V
$$

- To reduce the difference between measured and calculated results, the following factors snould be taken into account:

1) The material properties of concrete should be precisely measured.

2) The heat applied to the specimen should be precisely measured. In actual furnace conditions, radiative heat flux plays an inportant role. A properly estimated heat transfer coefficient is reeded.

3) Decomposition, which take place at much higher tomperatures, should bo precisely measured and taken into account. "Hese reactions also work as a heat sink.

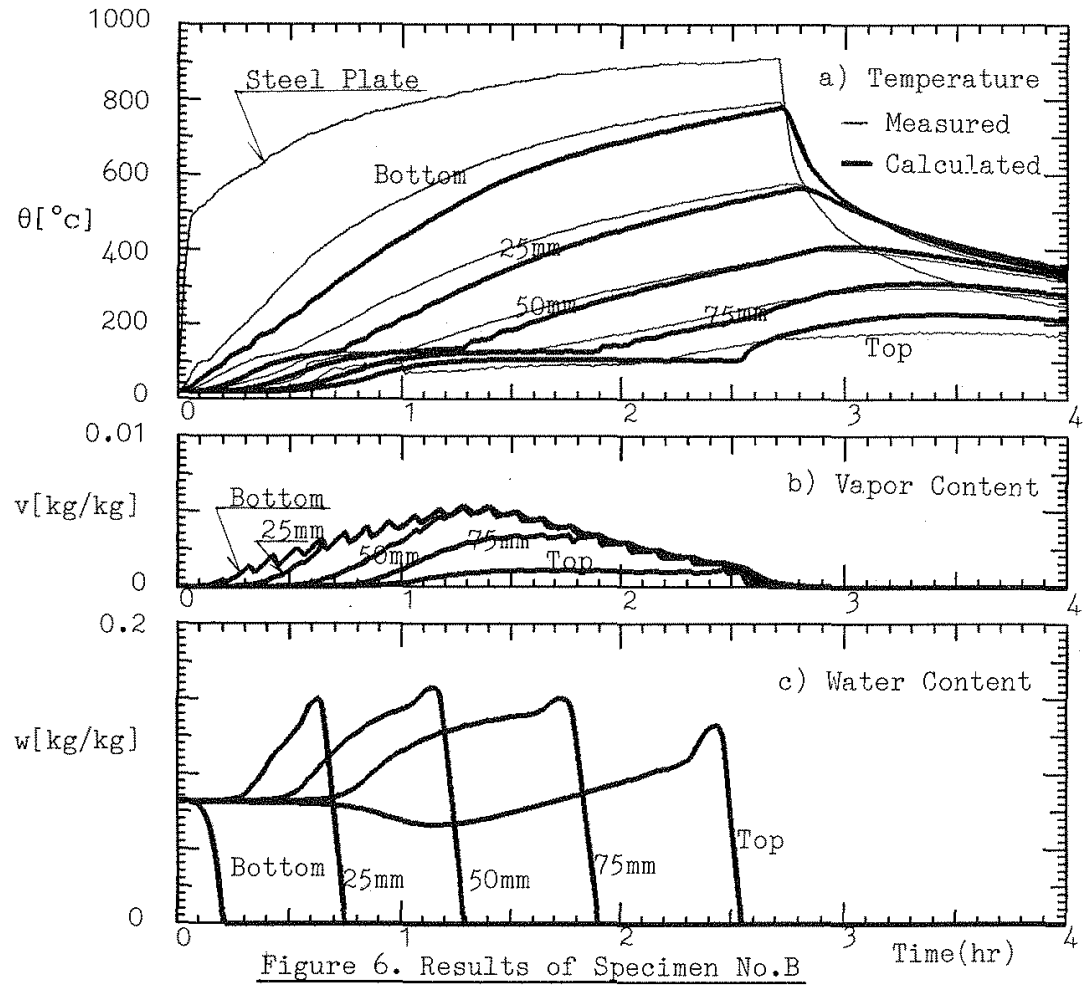




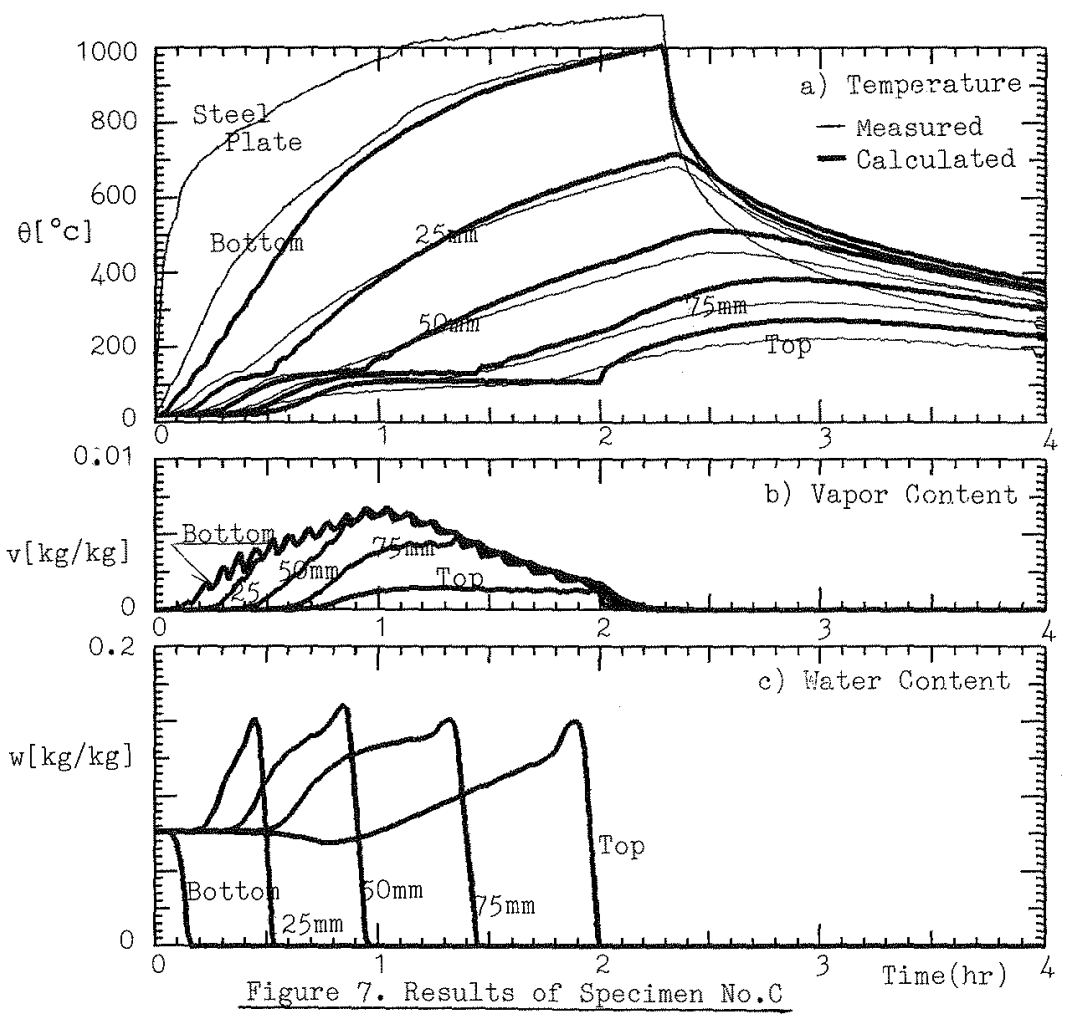

SUIMARY

Sample calculations based on the diffusion rodel are presented. In spite of the simplicity of this model, typical temperature histories of concrete exposed to test fires, agree reasonably well with the experiments.

\section{ACKNOWLHWGHEL}

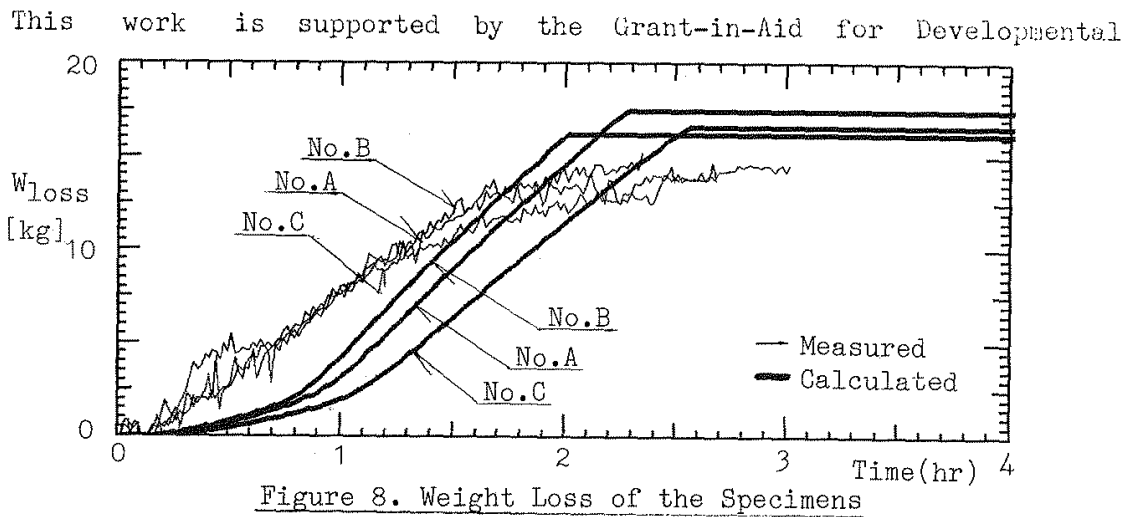


Scientific Research of Ministry of Education of Japan. Numerical calculation was carried out at the Data Processing Center of Kyoto University.

NOMENCLATURE

Symbols

A Frequency Factor

$\mathrm{C}_{\mathrm{s}}, \mathrm{n}_{\mathrm{s}}$ Constants in Equation(5)

D Diffusion Coefficient

$[1 / 5 e c]$

$\mathrm{E}_{\mathrm{d}}$ Inerey of Activation

$[\mathrm{J} / \mathrm{kg}]$

c Heat Capacity

$[\mathrm{J} / \mathrm{kgK} \mathrm{K}]$

$\left[\mathrm{m}^{2} / \mathrm{sec}\right]$

h Heat Iransfer Coefficient

$\left[\mathrm{W} / \mathrm{m}^{2} \mathrm{~K}\right]$

$\mathrm{h}_{\mathrm{v}}$ Vapor Transfer Coefficient $\left[\mathrm{kg} / \mathrm{min}^{2} \mathrm{Sec}\right]$

[X]

T Absolute Temperature

$R_{1 \infty}$ Rate of Local Evaporation $\left[\mathrm{kg} / \mathrm{m}^{3} \mathrm{Sec}\right]$

w Water Content

$\gamma \quad$ Evaporation Coefficient

[kg/kg]

$\left[\mathrm{kg} / \mathrm{m}^{3} \mathrm{Sec}\right]$

[ $\mathrm{C}]$

I Latent Heat

$[\mathrm{J} / \mathrm{hE}]$

$\checkmark$ Vapor Content

$[\mathrm{kg} / \mathrm{kg}]$

$R_{v}$ Cas Constant of Water Vapor $\left[\mathrm{Pa} \mathrm{m}^{3} / \mathrm{kg}\right]$

if Weight

[KE]

$\varepsilon$ Void Fraction

$\rho$ Lensity

$[\mathrm{W} / \mathrm{mK}]$

\section{Subscripts}

- Iry Concrete v Water Vapor $\mathrm{w}$ Iiquid Water eff Iff'fictive $f$ Furnace eq Equilikrium sat Saturated ini Initial.

\section{REFERENCES}

/1/ Kawagoe,K., "Calculation of Temperature in Double-layer walls heated from one side", Bull. of Fire Prevention Soc.Japan, 13-2, 29-35, 1965

/2/ Wakamatsu, F., "Heat Flow Analysis of Building Members during Fire Exposure", Trans. Architectura1 Institute of Japan,109,73-79, and 111,3136,1965

13/ Fujil,S.,"The Theoretical Calculation of Temperature of Thermally Protected Steel Column Exposed to the Fire",Bull. of Fire Prevention Soc. Japan, 13-1,13-21, 1965

/4/ Harmathy, T.Z., "Simultaneous Moisture and Heat Transfer in Porous Systems With Particular Reference to Drying", I\&EC Fundamenta1s,8-1,92103,1969

15/ Matsumoto,M., (in Japanese), Ph.D. dissertation, Faculty of Engineering, Kyoto university, 1978

$16 /$ Huang,C.L.D., Siang,H.H and Best,C.H, "Heat and Moisture Transfer in Concrete Slabs", Int.J.Heat Mass Transfer, 22, 257-266, 1979

17/ Sahota,M.S., and Pagni,P.J., Meat and Mass Transfer in Porous Media Subjected to Fires", Int.J.Heat Mass Transfer, 22, 1069-1081, 1979

/8/ Dayan, D., "Heat and Mass Transfer within an Intensely Heated Concrete Slab", Int.J.Heat Mass Transfer, 25,1461-1467,1982

19/ Young,D.M and Crowewll,A.D, "Physical adsorption of gases", Butterworth, 1962 
10/ Alexander,R, "Diagonally Implicit Munge-Kutta Methods for Stiff 0.D. $\mathrm{H}^{\prime \prime}$ "Sian J. limerical Analysis, 14-6,1006-1021,1977

/11/ Ueda, T. and Tokura,T., "An Experimental Study on Thermophysical Properties of Concrete at High 'Temperatures", Summaries of 'iechnical Papers of Annual Veeting, Series A, Architectural Institute of Japan, 761-766,1987 /12/ lasaka, S.,Yoshida, W. and Tarada,K.,"A Study on Temperature History in Concrete of Composite lloor in Fire", ibid, Series $1,761-766,1987$

13/ Method of fixe resistance test for structural parts of builainc." Japanese Incistria. Etardara, A 1304,1975 
